\title{
Papilomavírus humano associado a lesões de cérvice uterina
}

\author{
Human papillomavirus associated to uterine cervix lesions
}

\author{
Vânia Noronha, Wyller Mello, Luísa Villa, Arival Brito, Roberto Macêdo, Fátima \\ Bisi, Rosilda Mota, Kyio Sassamoto, Talita Monteiro e Alexandre Linhares
}

\begin{abstract}
Resumo Estudou-se a prevalência do papilomavírus humano (HPV) em 228 mulheres portadoras de lesões em cérvice uterina, atendidas no Instituto Ofir Loiola, em Belém, Pará, no período de março de 1992 a maio de 1996. As pacientes foram submetidas à biópsia de colo uterino, sendo o material encaminhado para histopatologia e pesquisa de HPV por PCR e hibridização por dot-blot. Distribuíram-se as participantes em três grupos, conforme diagnóstico histopatológico. O grupo A constituiu-se de 155 mulheres com carcinoma epidermóide invasor ou com adenocarcinoma, o grupo $B$ de 54 portadoras de neoplasia intraepitelial cervical grau II ou III, e o grupo C de 19 pacientes com cervicite crônica. Observaramse prevalências de HPV em 70,3\%, 63,0\% e 36,8\% das mulheres dos grupamentos $A, B$ e $C$, respectivamente, sendo o HPV 16 registrado em 60,4\% das amostras positivas do grupo $A$ e $54,5 \%$ daquelas do grupo $B$. Os tipos 16,18 e 33 representaram 71,4\% dos detectados no grupo $C$.
\end{abstract}

Palavras-chaves: Papilomavírus humano. HPV. Cérvice uterina. Carcinoma cervical. Neoplasia inraepitelial cervical

\begin{abstract}
It was studied the prevalence of human papillomavirus (HPV) among 228 women with lesions of uterine cervix attending the Ofir Loiola Institute, in Belem, Para, from March 1992 to May 1996. Histopathological examination was performed with all cervical biopsy samples obtained from these patients. In addition, specimens were analysed by both polimerase chain reaction and dot-blot hybridization to detect HPV DNA. The patients were assigned to three groups, according to the diagnosis made by histopathology, as follows: A, including 155 women suffering from invasive epidermoid carcinoma or adenocarcinoma; $B, 54$ patients having either cervical intraepithelial neoplasia grade II or III; and C, involving 19 women with chronic cervicitis. The prevalence rates of HPV in groups $A, B$ and $C$ were $70.3 \%, 63 \%$ and $36.8 \%$ respectively. HPV 16 accounted for $60.4 \%$ and $54.5 \%$ of types identified in groups $A$ and $B$, respectively. Altogether HPV types 16,18 and 33 were detected in $71.4 \%$ of positive patients belonging to group $C$.
\end{abstract}

Key-words: Papillomavirus. HPV. Uterine cervix. Cervical carcinoma. Cervical intraepithelial neoplasia.

\footnotetext{
Instituto Evandro Chagas (IEC), Instituto Ofir Loiola (IOL), Núcleo de Medicina Tropical da Universidade Federal do Pará (NMT/UFPA), Belém, PA, Brasil. Instituto Ludwig de Pesquisas sobre o Câncer, São Paulo, SP, Brasil.

Endereço para correspondência: Dra. Vânia Noronha. Instituto Evandro Chagas. Av. Almirante Barroso 429, Marco, 66090-000 Belém, PA, Brasil.

Fax: 5591 266-46-69 ou 226-1284.

Recebido para publicação em 28/4/98.
} 
Acredita-se que a infecção viral mais freqüentemente transmitida por via sexual seja aquela provocada pelo HPV 212 , originando também uma das mais prevalentes entre todas as doenças sexualmente transmissíveis.

Aimportância que assume hoje a nível mundial o estudo dos HPV vem de sua nítida correlação com os processos malignos e lesões precursoras em cérvice uterina.

Os papilomavírus (PV) são um dos dois gêneros da família Papovaviridae. Classificamse de acordo com sua espécie de origem (humana, bovina, etc) e conforme a homologia existente entre o material genético de vírus da mesma espécie. Atualmente, estão identificados mais de 70 tipos distintos de HPV16, sendo que cerca de 35 infectam o trato genital8.

O câncer cervical, com uma incidência mundial de cerca de 500.000 casos por ano ${ }^{11}$, constitui-se em um dos mais graves problemas de saúde pública, especialmente para os países em desenvolvimento ${ }^{1}$, dentre os quais o Brasil, onde se estima que cerca de 40.000 casos novos surjam anualmente26.

Evidências demonstram que as mulheres portadoras de certos tipos de HPV, especialmente o 16 e o 18, apresentam risco significativamente maior de desenvolver processo maligno em cérvice uterina quando comparadas àquelas sem sinais de infecção por esses agentes virais 1424 .

Com base no exposto, tornou-se premente a realização deste estudo cujo objetivo foi determinar a prevalência e identificar os tipos de HPV mais freqüentes em mulheres com lesões de cérvice uterina, agrupadas segundo diagnóstico histopatológico, em Belém, Pará.

\section{MATERIAL E MÉTODOS}

Foram testadas 228 amostras de cérvice uterina provenientes de biópsias de mulheres atendidas no Instituto Ofir Loiola (IOL), em Belém (Pará), no período de março/1992 a maio/1996, com suspeita clínica e/ou laboratorial (citologia) de processo maligno em região cervical e sem história de terapêutica antineoplásica. As coletas ocorreram após assinatura de termo de consentimento por parte das pacientes.

Os espécimes coletados foram armazenados em formol tamponado para posterior diagnóstico histopatológico no IOL, e em baixas temperaturas, inicialmente em nitrogênio líquido e a seguir em freezer, objetivando diagnóstico pela técnica de PCR no Instituto Evandro Chagas (IEC), Belém (Pará), e hibridização por dot-blot no Instituto Ludwig de Pesquisas sobre o Câncer, São Paulo (São Paulo).

As pacientes foram distribuídas em 3 grupos ( $\mathrm{A}, \mathrm{B}$ e $\mathrm{C}$ ), conforme diagnóstico histopatológico. Do grupo A (155/228) fizeram parte aquelas com adenocarcinoma (5/155) ou com carcinoma epidermóide invasor (150/155). As com neoplasia intra-epitelial grau II (1/54) ou III (53/54) (NIC II ou NIC III) foram incluídas no grupo B (54/228), e as com cervicite crônica constituíram o grupo C (19/228). A idade das mulheres variou de 16 a 86 anos, com médias de 51,5 (grupo A), 43,6 (grupo B) e 44,3 (grupo C).

A técnica de PCR utilizada baseou-se na descrição de Manos et al17, utilizando-se primers genéricos MY09 e MY11, que detectam ampla faixa dos diferentes tipos de HPV em uma área bem delimitada de seus genomas (região L1). Como controle de qualidade utilizaram-se primers capazes de amplificar um fragmento do gene de globina humana. Em todos os ensaios foram empregados controles positivos (células He-La ou células Caski) e negativos (água).

A reação foi efetuada acrescentando-se a $1 \mu \mathrm{l}$ de cada amostra do DNAa ser testado, $49 \mu \mathrm{l}$ de uma mistura (MIX) cuja composição era: $5,00 \mu \mathrm{l}$ de cada um dos 4 trifosfatos de desoxinucleotídeo, 1,00 $\mu \mathrm{l}$ de cada primer para HPV (MY09 e MY11), 0,50 $\mu$ de cada primer de

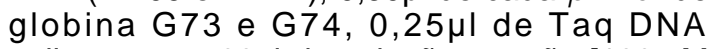
polimerase, $5,00 \mu \mathrm{l}$ de solução tampão $[100 \mathrm{mM}$ Tris- $\mathrm{Hcl}$ (pH:9), 500mM KCl, 30mM MgCl2] e $35,75 \mu l$ de água bidestilada, completando assim um volume total de $50 \mu \mathrm{l}$. As misturas foram, em seguida, submetidas a 33 ciclos de amplificação em aparelho ciclador de temperatura $\left(94^{\circ} \mathrm{C}\right.$ por $1 \mathrm{~min}, 55^{\circ} \mathrm{C}$ por $1 \mathrm{~min}, 72^{\circ} \mathrm{C}$ por $2 \mathrm{~min}$, seguidos ao final por $10 \mathrm{~min}$ a $72^{\circ} \mathrm{C}$ ).

Após eletroforese em gel de agarose a $2 \%$, os produtos da PCR foram corados em solução de brometo de etídio e visualizados à luz ultravioleta.

A técnica de hibridização por dot-blot baseou-se na descrição de Manos et al17, com modificações. Utilizaram-se oligonucleotídeos específicos tornados radioativos pela incorporação de P32, em uma reação que 
envolveu a T4 polinucleotídeoquinase. Empregaram-se sondas específicas para os seguintes tipos de HPV: $5,11,16,18,26,31$, 33, 35, 39, 40, 42, 45, 51, 52, 53, 54, 55, 56, 57, 58, 59, 66, 68, 70, 72, 73, Pap.155, Pap.291, W13B (os três últimos são tipos ainda não classificados) e sonda genérica.

A décima parte do volume da reação de PCR foi desnaturada em placa de ELISA com hidróxido de sódio. A mistura foi pipetada sobre uma membrana de náilon ajustada a uma placa de acrílico (dot-machine), ligada constantemente ao vácuo. A membrana foi removida e colocada sobre um papel de filtro para marcar as posições das amostras. Fixou-se o DNA expondo a membrana à luz ultravioleta por 5 minutos. A membrana foi colocada em saco plástico com a seguinte solução de hibridização: [6x solução citrato salina padrão (SSC): $(\mathrm{NaCl} \rightarrow 900 \mathrm{mM}$, $\mathrm{Na}$ citrato $\rightarrow 90 \mathrm{mM}) ; 10 \times$ Denhardt's: $(0,2 \%$ de soro de albumina, $0,2 \%$ de polyvinylpirrolidona, $0,2 \%$ ficoll) $; 0,5 \%$ de SDS, $100 \mu \mathrm{g} / \mathrm{ml}$ de esperma de salmão desnaturado] e incubou-se por $3 \mathrm{~h}$ a $56^{\circ} \mathrm{C}$. A seguir a sonda radioativa foi acondicionada no interior do saco plástico junto com a solução de hibridização e incubada por $12-18$ horas a $56^{\circ} \mathrm{C}$, após o que as membranas foram removidas do saco plástico e lavadas a temperatura ambiente por duas vezes, por 15 minutos cada, seguindo-se duas vezes a $56^{\circ} \mathrm{C}$ por 20 minutos, com uma solução de $2 \times$ SSC e 0,1 SDS. No final as membranas foram expostas a filmes de raio $X$ por períodos de 12 a $24 \mathrm{~h}$.

A tipagem dos HPV foi realizada nas amostras que amplificaram ou não 450 pares de bases da região L1 dos HPV.

\section{RESULTADOS}

Todas as amostras foram testadas por PCR, enquanto que pela hibridização por dot-blot analisaram-se 147 (de um total de 150) no grupo A, 49 (das 54) no grupo B e 17 (das 19) no grupo $\mathrm{C}$.

Consideraram-se positivas para HPV as amostras nas quais a presença do vírus foi detectada por ambas as técnicas (136/150), aquelas positivas por dot-blot e negativas por PCR (10/150), e as positivas por PCR e não testadas por dot-blot (4/150), conforme pode ser observado na Tabela 1.

Aprevalência de HPV foi de 70,3\% (109/155) no grupo A, 63,0\% (34/54) no B e 36,8\% (7/19)

Tabela 1 - Presença de papilomavirus humano em lesões de cérvice uterina, pelas técnicas de PCR e hibridização por dot- blot, segundo os grupos estudados*, Belém, Pará (1992-1996).

\begin{tabular}{lcccc}
\hline Grupos & $\begin{array}{c}\text { Positivas por } \\
\text { dot-blot e PCR }\end{array}$ & $\begin{array}{c}\text { Positivas por } \\
\text { dot-blot e negativas por PCR }\end{array}$ & $\begin{array}{c}\text { Positivas por PCR e } \\
\text { dot-blot não realizado }\end{array}$ & Total \\
\hline A & 100 & 6 & 3 & 109 \\
B & 30 & 3 & 1 & 34 \\
C & 6 & 1 & - & 7 \\
\hline Total & 136 & 10 & 4 & 150 \\
\hline${ }^{*}$ Ambulário
\end{tabular}

no C (Tabela 2). Verifica-se ainda, na mesma tabela, que o grupo A se constituiu predominantemente de mulheres com diagnóstico histopatológico de carcinoma epidermóide invasor (150/155), enquanto que o grupamento $B$ foi representado quase que exclusivamente por pacientes com NIC III (53/54).

A Figura 1 demonstra que nas 106 amostras pertencentes a mulheres do grupo A em que 0 HPV foi detectado por dot-blot, encontrou-se nítido predomínio do tipo 16 com $60,4 \%$ do total (64/106); o HPV 18 contribuiu com 11,3\% (12/106), incluindo-se neste grupo um espécime que foi simultaneamente positivo para HPV 6,
11 e 18. Os HPV 31, 33, 45, 52, 58, 59, 73 representaram, em conjunto, 18,9\% (20/106), sendo que o HPV 73 contribuiu com apenas 0,9\% (1/106) e, em 9,4\% (10/106) houve reação positiva na sonda genérica, significando, provavelmente, a presença de outros tipos de HPV para os quais sondas moleculares específicas não estão disponíveis.

Nas 33 amostras do grupo B em que a hibridização por dot-blot demonstrou a presença do vírus, observa-se (Figura 2) que o HPV 16 representou 54,5\% (18/33), o HPV 18 apenas $3 \%(1 / 33)$; os tipos 31,33 e 58 concorreram com $21,2 \%$ (7/33); e, em 21,2\% (7/33) a presença de 
Tabela 2 - Prevalência de papilomavirus humano em lesões de cérvice uterina pelas técnicas de PCR e hibridização por dot-blot, segundo os grupos estudados*, Belém, Pará (1992-1996).

\begin{tabular}{|c|c|c|c|c|c|c|}
\hline \multirow[t]{2}{*}{ Grupos } & \multirow{2}{*}{$\begin{array}{c}\text { Diagnóstico } \\
\text { histopatológico }\end{array}$} & \multirow[t]{2}{*}{$\mathrm{n}^{0}$} & \multicolumn{2}{|c|}{ Presença de HPV } & \multicolumn{2}{|c|}{ Ausência de HPV } \\
\hline & & & $\mathrm{n}^{0}$ & $\%$ & $\mathrm{n}^{0}$ & $\%$ \\
\hline \multirow[t]{3}{*}{$\bar{A}$} & Adenocarcinoma & 5 & 4 & 80,0 & 1 & 20,0 \\
\hline & Carcinoma epidermóide invasor & 150 & 105 & 70,0 & 45 & 30,0 \\
\hline & subtotal & 155 & 109 & 70,3 & 46 & 29,7 \\
\hline \multirow[t]{3}{*}{ B } & NIC II & 1 & 1 & 100,0 & 0 & 0,0 \\
\hline & NIC III & 53 & 33 & 62,7 & 20 & 37,3 \\
\hline & subtotal & 54 & 34 & 63,0 & 20 & 37,0 \\
\hline $\mathrm{C}$ & Cervicite crônica & 19 & 7 & 36,8 & 12 & 63,2 \\
\hline Total & & 228 & 150 & 65,8 & 78 & 34,2 \\
\hline
\end{tabular}

${ }^{\star}$ Ambulatório do Instituto Ofir Loiola.

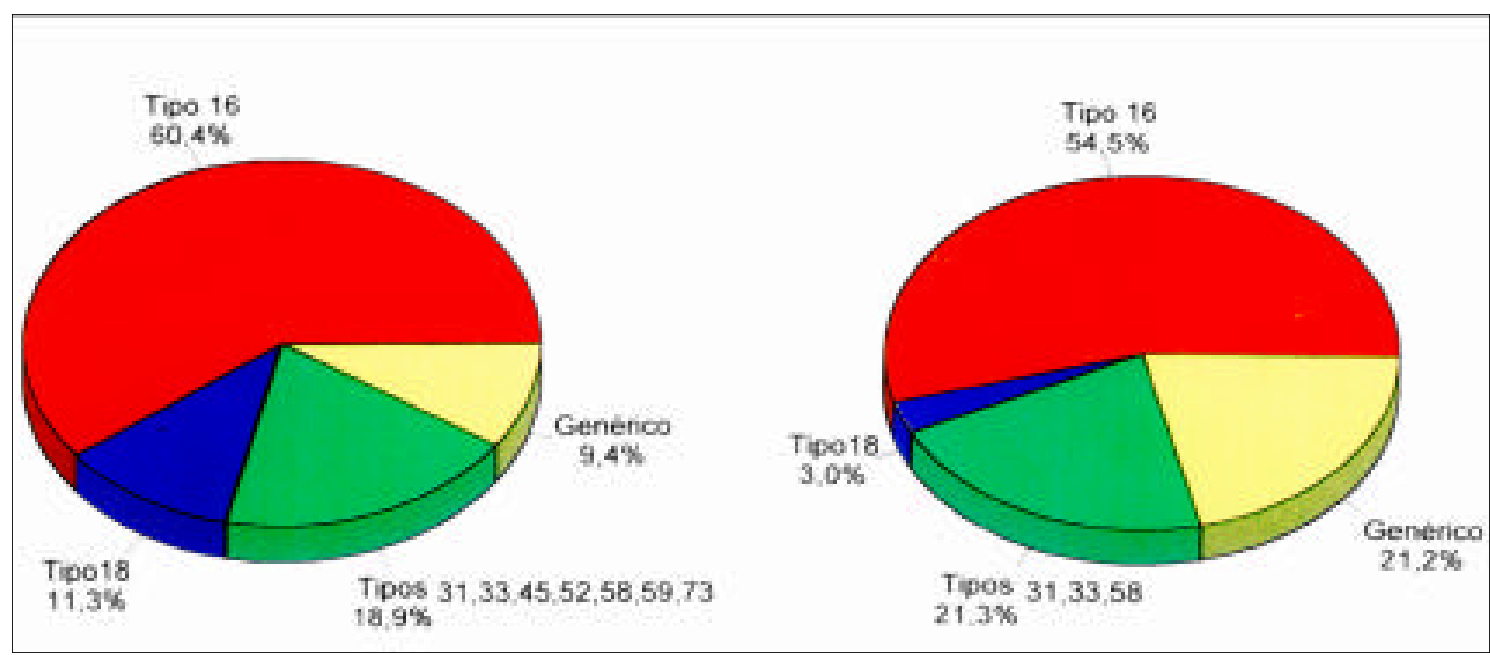

Figura 1 - Tipos prevalentes de HPV em 106 amostras de cervice uterina, de pacientes do grupo A (Ambulatório do IOL), pela técnica de hibridização por dot-blot, Belém, Pará (1992-1996).

Figura 2 - Tipos prevalentes de HPV em 33 amostras de cervice uterina, de pacientes do grupo B (Ambulatório do IOL), pela técnica de hibriđização por dot-blot, Belém, Pará, (1992-1996).

HPV foi detectada somente pela sonda genérica.

No grupo $C$, das 7 amostras positivas por dot-blot, $5(71,4 \%)$ pertenciam aos

seguintes tipos: 16,18 ou 33 , enquanto a sonda genérica mostrou-se positiva em 2 casos (dados não exibidos em figura).

\section{DISCUSSÃO}

O percentual de HPV detectado em amostras de mulheres com carcinoma de colo uterino no presente estudo está em concordância com o referido pela literatura especializada que situa a prevalência na faixa de 70 a $90 \%$ quando utilizadas técnicas laboratoriais similares, em sensibilidade, às empregadas neste estudo. De Brinton et al 7 e
Muñoz et al19, por meio da metodologia de PCR, em espécime clínico obtido por meio de biópsia de cérvice uterina, apresentaram resultados que consubstanciam nossos dados. Percentuais dentro dos mesmos níveis foram também encontrados em material coletado por meio de esfregaços ou raspagens de região cervical uterina4 10 . 
O grupo B, constituído quase que exclusivamente de mulheres diagnosticadas como portadoras de NIC III (apenas uma possuía NIC II), apresentou $63 \%$ de amostras positivas para HPV (Tabela 2). Estabelecendo comparação com o trabalho de Muñoz et al19, verificamos que esses autores encontraram prevalências de $70,7 \%$ e $63,2 \%$ em pacientes com carcinoma in situ estudadas na Espanha e Colômbia, respectivamente.

Cumpre ressaltar que as alterações designadas como carcinoma in situ e displasia severa21, em virtude do elevado grau de dificuldade na distinção histológica que por vezes apresentam, passaram a ser mais freqüentemente agrupadas sob a denominação de NIC III22, daí a comparação estabelecida entre os resultados locais e aqueles de Muñoz et al19.

É pertinente comentar que resultados positivos superiores a $90 \%$ já foram detectados. Liaw et al ${ }^{15}$, em amostragem agrupando mulheres com NIC II, NIC III e carcinoma invasivo revelaram prevalência de $92 \%$, utilizando amostras coletadas por raspagens de cérvice uterina. Na Hungria, Kónya et al13 registraram presença de HPV em 98\% das amostras, obtidas por meio de biópsia, de pacientes com carcinoma cervical invasivo. Em estudo 3 realizado com mais de 1.000 espécimes clínicos oriundos de mulheres com carcinoma invasivo de colo uterino, residentes em 22 países, encontrou-se DNAde HPV em 93\% das amostras, não sendo registrada diferença significativa entre os resultados positivos dos diversos países 3 .

A caracterização antigênica dos HPV, revelando nítida predominância do tipo $16 \mathrm{em}$ lesões neoplásicas, foi de cardinal importância (Figura 1 e Figura 2), pois demonstrou que os achados em nossa região corresponderam aos que vêm sendo registrados por diversos autores em áreas geográficas distintas 10 19. Estudo realizado em Barbados 20 com 20 mulheres portadoras de carcinoma em região cervical (19 das quais em cérvix uterina), demonstrou presença de HPV 16 em $65 \%$ dos casos. A pesquisa de Bosch et al3, já referida anteriormente, detectou que $50 \%$ das amostras testadas foram positivas para HPV 16.
Ainda em relação aos tipos de HPV, notamos que cerca de $90 \%$ e $79 \%$ dos identificados nos grupos Ae B, respectivamente, são considerados de risco para processos malignos e lesões precursoras em região cervical15. Nesse contexto, nossos percentuais situam-se entre os de ElufNeto et al 10 e Liaw et al 15 . Os primeiros registraram que entre mulheres com carcinoma cervical uterino e portadoras de HPV, o percentual de amostras positivas para os tipos 16, 18, 31, 33 , foi de $78 \%$. O segundo trabalho, efetuado em grupamento de pacientes com diagnóstico de NIC II, NIC III e carcinoma invasor, demonstrou que aquelas positivas para HPV estavam infectadas com tipos considerados de risco para progressão oncogênica em $98 \%$ dos casos.

O registro de amostras positivas com a sonda genérica, que correspondeu a $9,4 \%$ e $21,2 \%$ nos grupos A e B, respectivamente (Figuras $1 \mathrm{e}$ 2), sugere o envolvimento de outros tipos de HPV cujas sondas moleculares não estão disponíveis.

Vale destacar nesta investigação a presença relativamente elevada de HPV considerados de alto risco (para o desenvolvimento de lesão maligna em colo de útero), em mulheres com diagnóstico histopatológico de cervicite crônica, embora a detecção de HPV em pacientes com alterações mínimas e mesmo sem alterações de colo uterino, não se constitua em um achado extraordinário5 691518 25. Roteli-Martins et al23 detectaram prevalência de HPV com potencial oncogênico em $38 \%$ das amostras com diagnóstico histopatológico de cervicite. Em nossa casuística o percentual de HPV foi de $37 \%$ (7/19), sendo que em $26 \%$ (5/19) os tipos corresponderam aos associados a processos carcinogênicos e em 11\% (2/19) não foi possível identificar-se o HPV presente no material examinado, logo se levarmos em conta apenas aqueles em que o HPV foi detectado (7/19), verificaremos que em $71 \%(5 / 7)$ deles confirmou-se tipos relacionados a processos malignos.

Acreditamos que os resultados aqui discutidos reforçam a correlação entre certos tipos de HPV, especialmente o 16, no desenvolvimento de lesão maligna de cérvice uterina.

\section{REFERÊNCIAS BIBLIOGRÁFICAS}

1. Aleixo Neto A. Aspectos epidemiológicos do câncer cervical. Revista de Saúde Pública 25:326-333, 1991.

2. Becker TM, Stone KM. Genital human papillomavirus infection. A growing concern. Obstetrics and Gynecology Clinics of North America 14:389-396, 1987.
3. Bosch FX, Manosm M, Munõz N, Sherman M, Jansen AM, Peto J, Schiffman MH, Moreno V, Kurman R, Shah KV. Prevalence of human papillomavirus in cervical cancer: a worldwide perspective. International biological study group. Journal of the National Cancer Institute 87:796-802, 1995. 
4. Bosch FX, Muñoz N, de Sanjosé S, Izarzugaza I, Gili M, Viladiu P, Tormo MJ, Moreo P, Ascunce N, Gonzalez LC, Taafur I, Kaldor JM, Guerrero E, Aristizabal N, Santamaria M, Alonso de Ruiz P, Shah K. Risk factors for cervical cancer in Colombia and Spain. International Journal of Cancer 52:750-758, 1992.

5. Cavalcanti SMB, Frugulhetti ICPP, Passos MRL, Fonseca MEF, Oliveira LHS Prevalence of human papillomavirus DNA in female cervical lesions from Rio de Janeiro, Brazil. Memórias do Instituto Oswaldo Cruz 89:575-580, 1994.

6. Chang DY, Chen RJ, Lee SC, Huang SC. Prevalence of single and multiple infection with human papillomaviruses in various of cervical neoplasia. Journal Medical Microbiology 46:54-60, 1997.

7. De Brinton RC, Hildeshein A, De Lao SL, Brinton LA, Sathya $P$, Reeves W. Human papillomaviruses and other influences on survival from cervical cancer in Panama. Obstetrics and Gynecology 81:19-24, 1993.

8. De Villiers EM. Human pathogenic papillomavirus types: an update. Current Topics In Microbiology and Immunology 186:1-12, 1994.

9. De Villiers EM, Schneider A, Miklaw H, Papendick U, Wagner D, Wesch $\mathrm{H}$, Wahrendorf J, zur Hausen $\mathrm{H}$. Human papillomavirus infections in women with and without abnormal cervical cytology. The Lancet 2:703706, 1987.

10. Eluf Neto J, Booth M, Muñoz N, Bosch FX, Meijer, CJLM, Walboomers JMM. Human papillomavirus and invasive cervical cancer in Brazil. British Journal of Cancer 69:114-119, 1994.

11. Fisher SG. Epidemiology: a tool for the study of human papillomavirus - Related carcinogenesis. Intervirology 37:215-225, 1994.

12. Jacyntho $\mathrm{C}$, Almeida Filho $\mathrm{G}$. Introdução-Histórico. In: Jacyntho C, Almeida Filho G, Maldonado P (eds) HPV. Infecção Genital Feminina e Masculina. Revinter, p.1-4, 1994.

13. Konya J, Veress G, Hernádi Z, Soós G, Czeglédy J, Gergeley L. Correlation of Human Papillomavirus 16 and 18 with prognostic factors in invasive cervical neoplasias. Journal of Medical Virology 46: 1-6, 1995.

14. Koutsky LA, Holmes KK, Critchlow CW, Stevens CE, Paavonen J, Beckmann AM, De Rouen TA, Galloway D.A, Vernon D, Kiviat NB. A cohort study of the risk of cervical intraepithelial neoplasia grade 2 or 3 in relation to papillomavirus infection. The New England Journal of Medicine 327:1272-1278, 1992.

15. Liaw K-L, Hsing AW, Chen C-J, Schiffman MH, Zhang TY, Hsieh C-Y, Greer CE, You S-L, Huang TW, Wu T-C, O' Leary TJ, Seidman JD, Blot WJ, Meinert CL, Manos
MM. Human papillomavirus and cervical neoplasia: a case-control study in Taiwan. International Journal of Cancer 62:565-571, 1995.

16. Longuet $M$, Cassonnet $P$, Orth $G$. A novel genital human papillomavirus (HPV), HPV type 74 , found in immunosupressed patients. Journal of Clinical Microbiology 34:1859-1862, 1996.

17. Manos MM, Ting T, Wright DK, Lewis AJ, Broker TR, Wolinsky, SM. The use of polymerase chain reaction amplification for the detection of genital human papillomaviruses. Cancer Cells 7:209-214, 1989.

18. Meyer MP, Carbonell RI, Mauser NA, Kanbour AI, Amrotegui MD. Detection of human papillomavirus in cervical swab samples by ViraPap and in cervical biopsy specimens by in situ hibridization. Human Pathology 100:12-17, 1993.

19. Muñoz N, Bosch FX, De Sanjosé S, Viladiu P, Tormo J, Moreo P, Ascunce N, González L.C, Tafur L, Gili M, Izarzugaza I, Guerrero E, Aristizábal N, Santamaria M, De Ruiz PA, Shah KV. El virus del papiloma humano en la etiologia del cancer cervicouterino. Boletin de la Oficina Sanitaria Panamericana 115:301-308, 1993.

20. Prussia PR, Ter Schegget J, Smits HL. Detection of oncogenic HPV DNAby a consensus polymerase chain reaction method in genital carcinomas in twenty women in Barbados. Western Indian. Medical Journal 42:144146, 1993.

21. Reagan JW, Seidemann IL, Saracusa Y. Cellular morphologic of carcinoma in situ and displasia or atypical hyperplasia of uterine cervix. Cancer 6:224-235, 1953.

22. Richart RM. The natural history of cervical intraepithelial neoplasia. Clinical Obstetrics and Gynecology 10:748784, 1967.

23. Roteli-Martins C, Derchain SFM, Dores GB, Siqueira SAC, Alves VAF, Panetta K. Associação entre diversos tipos de HPV e outras infecções vaginais com lesões intraepiteliais cervicais de alto grau. Revista Brasileira de Doenças Sexualmente Transmissíveis 1:9-14, 1996.

24. Schiffman MH, Bauer HM, Hoover RN, Glass AG, Cadell DM, Rush BB, Scott DR, Sherman ME, Kurman RJ, Wacholder S. Epidemiologic evidence showing that human papillomavirus infection causes most cervical intraepithelial neoplasia. Journal of the National Cancer Institute 85:958-964, 1993.

25. Shroyer KR, Lovelace GS, Abarca ML, Fennel RH, Corkill ME, Woodard WD, Davilla GH. Detection of human papillomavirus DNA by in situ hybridization and polymerase chain reaction in human papillomavirus equivocal and dysplastic cervical biopsies. Human Pathology 24:1012-1016, 1993. 